\title{
Impact of Risk Management towards Sustainability of Microfinance Industry in Sri Lanka: A Case Study
}

\author{
Anurudha Gishan Illangakoon' ${ }^{1}$ (D) S. M. Ferdous Azam² ${ }^{\text {iD, Adam Amril Jaharadak }}{ }^{3}$ \\ ${ }^{1,2,3}$ Department Postgraduate Centre, Management and Science University, University Drive, Off Persiaran Olahraga, Section 13, 40100, Selangor, Malaysia
}

Keywords: Government
of Sri Lanka, Central
Bank, Microfinance
Institutes, Risk
Management, Self Helped
Groups (SHG),
Microfinance information
exchanges (MIX).

exchanges (MIX)

Received Date:

24-08-2021

Accepted Date:

22-09-2021

Publication Date:

$31-12-2021$

\section{ABSTRACT}

Purpose of the study: The microfinance industry has been developed significantly last two decades. It is fast becoming a household name globally and one of the key contributors to socialeconomic development. The Sustainability of the microfinance industry depends on several factors and encounters numerous challengers. The purpose of the study is to examine whether there is a relationship between risk management and the sustainability of the microfinance industry in Sri Lanka.

Methodology: A simple regression analysis is used to demonstrate a connection in which one independent variable is predicted to influence one dependent variable. The study included 376 microfinance women borrowers from three districts in Sri Lanka, and the cluster sampling approach was used. Primary data was gathered using surveys, while secondary data was collected from CBSL, MFI annual reports, and the Microfinance Information Exchanger (MIX).

Main Findings: The study findings reveal that effective risk Management has a significantly positive relationship with the Suitability of the Microfinance Industry in Sri Lanka.

Research limitations/implications: The study was limited to three districts out of 25 districts in Sri Lanka, and the sample frame was selected from three leading MFIs that agreed to participate in the research. The availability of time for this study was limited and could not permit the consideration of all MFIs and the entire country.

Novelty/Originality: The study concludes that MFIs should have a proper and effective risk management process, but it should be adequately handled and communicated to borrowers. It implies that proactive risk management is essential to the long-term Sustainability of microfinance institutions (MFIs).
(C)2021 by author(s). This is an Open Access article distributed under the terms of the Creative Commons Attribution License 4.

Please cite this article as: Illangakoon, A. G., Azam, S. M. F., \& Jaharadak, A. A. (2021). Impact of Risk Management towards Sustainability of Microfinance Industry in Sri Lanka: A Case Study. International Journal of Social Sciences and Economic Review, 3(4), 0107.

doi.org/10.36923/ijsser.v3i 4.117

Read online:

Scan this QR code with your smart phone or mobile device to read online.

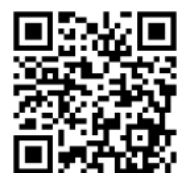

\section{INTRODUCTION}

Predominately, the Microfinance concept evolved as a tool to eradicate poverty and support poor communities to uplift financial and social wellbeing. In other words, Microfinance is set up to support a particular segment of the community who were unable to approach conventional banks (AlTamimi, 2002; Bhatt \& Tang, 2001). Whist growing the industry, MFIs encounter and face challenges how to manage different risk dimensions, mainly credit, liquidity, Operational risk due to rising competition, complexity in the market, volatile economic conditions, social environment, natural disasters, climatic changes pandemics mainly in developing nations (Fernando, 2007). In this scenario, you cannot evade risk but need to manage risk in such a manner. The participation of all stakeholders needs to adopt adequate controls, processors, frameworks, and strategies to sustain the industry, which should safeguard all stakeholders in the industry,y mainly MFIs and clients. One cannot face challenges in isolation. Managing risk is significant and vital in the industry. Management of risk is not a new sensation but giving preference and prominence is very important. It has become the most significant priority among financial institutions after financial debacles and crises. It is observed that Risk management and Compliance behave are the essential words in the financial industry. As per the Risk Management Initiative in Microfinance (RIM), "the possibility of adverse events occurring and their potential for financial losses and negative social performance".Risk-taking in our life and business is a natural element and essential part. Without taking risks, we will not be able to generate a return or satisfaction. There is a common saying, "high-risk, high return and lowrisk low return". Predominantly microfinance industry, in particular, deals with a highly risky environment and customer segment. This necessitates that may effective risk management is vital to the long-term Sustainability of microfinance institutions (MFIs). Risk is an important component of financial services or any other industry. There are multiple types of risk factors involved in financial services more than other industries and businesses. When financial institutions avail credit facilities, it creates counterparty risk of default. The major threat would arise as a result of the viral 
effect on the failure of one microfinance company to another, subsequently impacting the entire industry. Hence it is of paramount importance to inculcate well discipline and control mechanism of the risk management process to the microfinance industry. This article gives a snapshot of different risk aspects, discussion of how to mitigate and fine-tune existing risk factors towards the Sustainability of the microfinance industry.

\section{LITERATURE REVIEW}

The primary literature sources have been extracted from World Bank research reports, Intentional policy studies, Central Bank of Sri Lanka, BASEL journals, Thesis and other published articles. There are numerous pieces of literatures in Risk management and Microfinance, nevertheless hardly revived literature that combines both concepts and framework. As per Khakhrisal (2009) risk has been defined as "an uncertainty of outcome that affects the objectives' that is a two-sided coin; on one side it has threat, and on the other, it has an opportunity". Risk is an integral and inherent part of any business, and therefore, MFIs are no exception. Unlike other financial institutions, Microfinance should focus special attention on the security risk aspect due non the availability of certain risk mitigant options such as collaterals, guarantees, asset pledges, etc. But this does not mean that MFIs should avoid risk-taking and curtail lending. The strategy should be optimizing the risk-reward or risk efficiency tradeoff (Al-Tamimi \& Al-Mazrooei, 2007; Khakhrisal, 2009). Without taking the risk, you may not be able to do business or generate a return. MFIs or other financial institutes take the risk, an essential component and vital part of financial services. Risk and reward are the fundamental components of doing business and taking risks. A proactive and effective risk management approach is essential to the long-term Sustainability of MFIs. As per Microfinance Insights Blog (2009) stated that "a few years ago, all were talking about competition and 'crowding out' in the microfinance sector, now we're talking more about resilience and survival of the fittest', which show the changes that have been taken place in the industry.

Oluyombo and Olabisi (2008) mentioned that it is very important to manage risk in order to avoid any financial and social assets losses need uninterrupted supply of funding to end-users of microfinance as and when they needed with proper assessment. There a number of arguments and gaps have been raised that modern trend in microfinance needs to redesign microfinance risk management. It is a known fact that the complexity of current financial systems, structures, change in the objectives, variability of recipients and institutions involved necessitate a more structured approach to risk management (Ilbert et al., 2006). As per

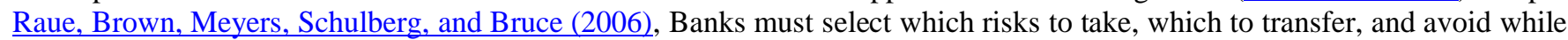
managing risk. If banks have those alternatives in terms of risk exposure, do microfinance institutions have the same?

The primary and vital features of sound risk management could be easily described in the abstract, but it is quite difficult to apply across the board and need to apply case-by-case. Each scenario and situations are unique, evolved around the roles and capabilities of individuals, objectives of the institutions, structure, activities. Of course, what works for one institution or individual maybe not fit another. Meyer (2002) stated that "sound or adequate risk management system is ever-changing, as new technology accommodates innovation and better information and as market efficiency grows". He further mentioned that "to remain competitive, institutions must adapt and constantly improve their process. That fact becomes clearer every day". Risk management is mainly focused on reducing earning volatility and avoiding significant losses. One proper risk management procedure needs to identify the risk, measure and quantify risk, then develop a strategy to manage risk (Kalu, Shieler, \& Amu, 2018). It is a proven fact that risk management is an essential part of maintaining the quality of the asset book, both liquid and illiquid assets, not only that safeguard the depositors' funds to ensure the industry's sustainability. It is an evident and imperative point that risk management of the MFIs should give clear directions and set goals from top to bottom; if not, risk management could not be achieved. MFIs should not take for granted that money will come and growth may be finite. It is very important that MFIs should grow at a decent pace, and more emphasis should be given towards Sustainability and survival in the long run. In today's context, it is observed that most of the MFIs in Sri Lanka adapt short term strategies to generate a high return and then exit from the business. Saturation of existing operational areas before large-scale horizontal expansion may be a better growth strategy, reducing cost and increasing efficiency in caseload and overall management (Guardiola-Albert et al., 2020). Hence, the first step is to create a stated objective and motivation from the owners and management to manage risk on a daily basis before it arises and/or as it becomes recognized.

Himang et al. (2020) stated that "experience has shown that the core principles and practices of microfinance are the same as those found in other environments", and hence depicts five basic "principles of financially viable lending". Those are demanddriven product development, operational efficiency, strong repayment discipline, sound financial performance, achieving scale. In order to achieve this, risk management plays a big role in the process. If MFIs risk management is not up to the mark, what would be the position of sound financial performances, maintain repayment discipline. Even if you have demand-driven products, what is the use if Nonperforming advances (NPA) are skyrocketing, which impacts operational efficiency. All are interlinked, and managing risk is critical for long term sustainability. Out of a number of components in Risk management, Credit risk plays a very important.

Like any banking industry, default rates vary. Grameen Bank, the Bangladeshi bank widely regarded as one of the sector's pioneers, reported a default rate of just 0.41 per cent in its 2017 annual report - a desirable result for any commercial bank. Notably, the bank's chairman cited the "high level of trust and goodwill between the bank and its borrowers" as contributing to the credit record, showing how microfinance can become woven into local communities (Asadli, de Mesquita, \& Kazantseva).

Numerous studies have discovered the importance of risk management and its impact on profitability, which shows statistical significance to the Sustainability of the industry. Hallunovi and Berdo (2018) found a significant and positive relationship between bank Return on equity (ROE) and credit risk management. Furthermore, Ndoka and Islami (2016) MFIs risk management systems and capacity building initiatives have mostly focused on financial and operational ris TheThey fund that if NPL increases by 1 unit, profitability as measured by ROA will reduce by 0.2869 units and the variable ROE by 0.018582 units. 
MFIs face many risks that threaten their long-term viability and sustainability, Careful screening, monitoring and evaluation, accurate reporting, and a strong credit (Razzaq, Maqbool, \& Hameed, 2019; Rozzani, Mohamed, \& Yusuf, 2017). The next stage in this article would take the discussions and recommendations derived and taken into consideration various literate and empirical studies in this study where one independent variable -Risk Management is hypothesized to affect one dependent variable - The sustainability of the microfinance industry in Sri Lanka.

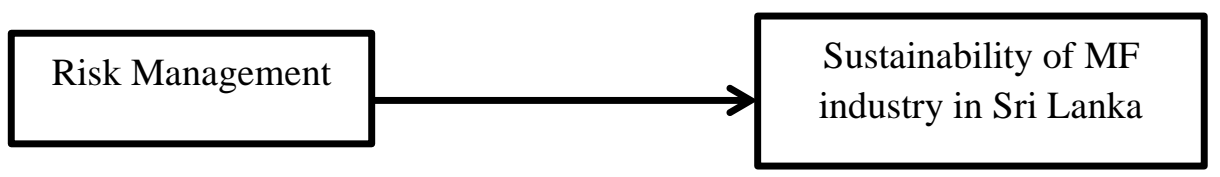

Figure 1: Conceptual framework

\section{RESEARCH METHODOLOGY}

The study was conducted with descriptive design, and a quantitative method was used to achieve the research objectives. The descriptive design is a method that enables to summary. It organizes data effectively and meaningfully, and the quantitative method was used to explain the data numerically. The population of this study was women who have taken microfinance facilities from different MFIs in Sri Lanka, and the sample was selected using cluster sampling method and clusters was selected considering the village there are so many groups in the community. Such as Self-helped groups (SHG), Activity and community bases subgroups, Farming Groups etc. Microfinance clients spread in different areas which carry heterogeneous and homogenous characteristics. Sample size has been decided in line with Krejcie and Morgan (1970)and Cohen (1988) decision on sample size.

The sample size is 376 microfinance borrowers selected from the population of approximately 20,000 in three districts in three major provinces in Sri Lanka and from three leading MFIs that agreed to participate in the research. The sampling frame was decided and screened through data from three leading microfinance company loan books. The target population was selected from Kalutara (Western Province), Puttalam (North Central Province), and Monaragala (Uva Province). Sample selection represents major provinces in Sri Lanka, which consist of all demographical characteristics and covers high-low economic indicators in Sri Lanka. Hence, it does not have any biases towards all three districts in one province. The research focused on getting feedback from microfinance borrowers in the target area. Hence, the unit of analysis is the individuals. The researcher gathered primary and secondary data. Secondary data sources included Central Bank Annual Reports, MFI annual financial statements, Census and Statistics Department data, and a questionnaire was utilized to obtain primary data. Because the survey is limited to specified small clusters in the Grama Niladari Division (GA), which is the smallest component of a divisional secretariat under the control of the federal government. Because the survey is limited to a certain geographic area and requires some interaction with the unit of analysis, physically administering the questionnaires is a viable way to gather data. The study's time horizon is cross-sectional, which indicates that data were gathered only once, maybe spanning a few weeks or months. Data collection has been slowed owing to the pandemic condition. This study evaluated the data using graphical methods, statistical methods, and basic regression analysis to identify the relationship between two variables.

\section{RESULTS AND ANALYSIS}

Four key demographic aspects, age, religion, number of dependents, and level of education, are selected as the sample's demographic aspects. Those aspects were analyzed using graphic presentation techniques, bar charts, and pie charts.

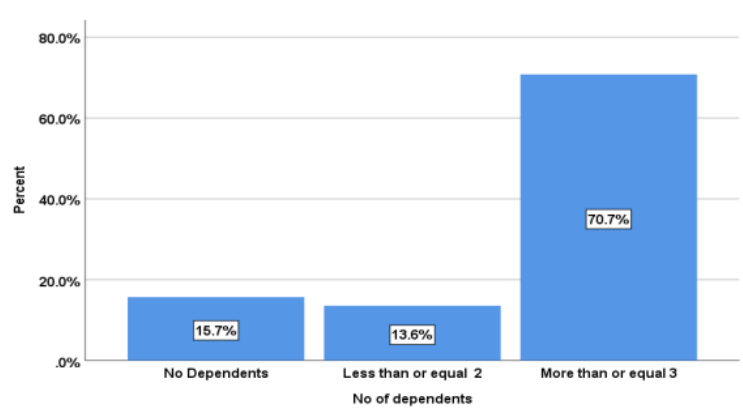

Figure 2: Number of dependents for each household

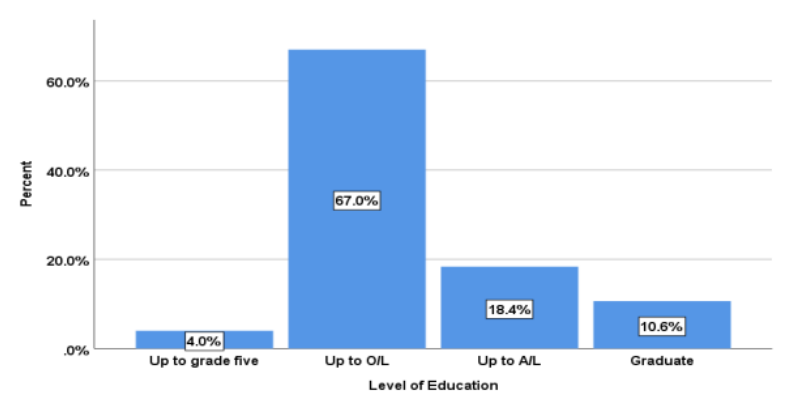

Figure 3: Education Level

Figure 2 emphasizes the number of dependents for each household. According to that, more than 70.7 per cent of respondents have more than or equal to three dependents in the family. Also, 13.6 per cent of families with less than or equal to 2 dependents in the family, and 15.7 per cent of respondents have no dependent on the family. Most women microfinance borrowers in Kalutara, Puttalam and Monaragala districts have more than three dependents in the family. The education level and literacy level play of clients play a key role in understanding the business and risk of the business. Figure 3 shows the level of education of the respondents of the sample. According to that, more of the respondents had studied up to O/L, and its portion is two-thirds of the sample. There is 18.4 per cent of respondents with education level up to A/L and 10.6 per cent of respondents up to 
graduate level. $\mathrm{n}$ addition to that, 4.0 per cent of respondents studied only up to grade five. It can be concluded that the majority of the women microfinance borrowers in the Kalutara, Puttalam and Monaragala districts have no proper level of education.

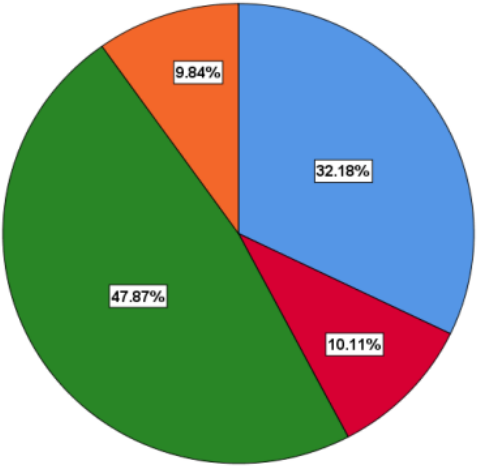

Figure 4: Type of Business Involved by the Respondents of the Sample.

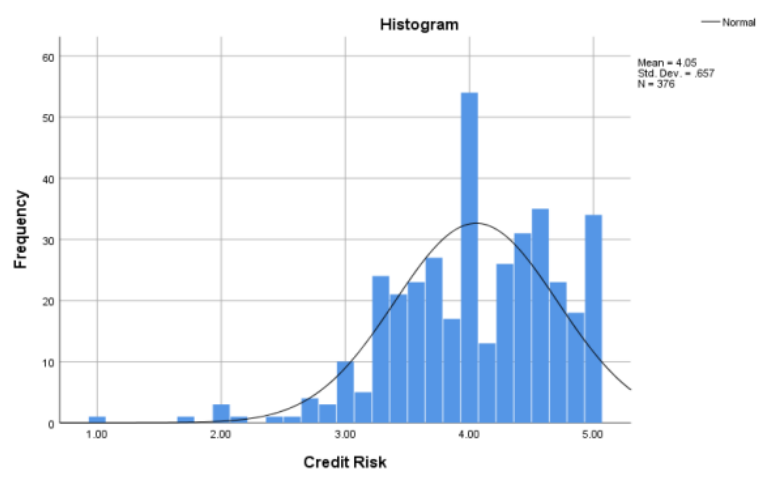

Figure 5: Histogram of Credit Risk

Figure 4 presents the type of businesses involved by microfinance borrowers. The majority of respondents have been involved in the manufacturing sector business, and its percentage is 47.87 per cent. Exactly 32.18 per cent of respondents are doing selfemployment, and 10.11 per cent involves agriculture and farming business. Also, 9.84 per cent of respondents involve service sector business. It can be concluded that more than 80 per cent of women microfinance borrowers in Kalutara, Puttalam and Monaragala districts engaged in manufacturing and self-employment related business

It was discussed that Credit risk is one of the major risk management components. The credit risk is a factor of risk management towards sustainable growth in the microfinance industry. Importance of effective Risk management process to MFIs to understand and assess the financial requirements of women microfinance clients towards industry sustainability in Sri Lanka, the descriptive analysis finds that the credit risk can be sustained through proper credit evaluation and decision-making process, proper knowledge sharing and monitoring process of MFIs, assessment of customer requirement and their financial disciplines and microfinance industry competition. As per the respondent view, those indicators significantly affected the risk management of the microfinance industry. Credit risk management in microfinance must be maintained for the business to be sustainable in Sri Lanka. Credit risk management determines the success and the survival of the microfinance industry (Kanake, 2014). According to credit risk management, the primary cause of the failure of microfinance institutions was poor portfolio management (Mbah \& Wasum, 2019). According to both prior and current studies, credit risk management may substantially impact the sustainability of the microfinance business.

As per the survey responses, the mean response of the credit risk related statements is 4.0540 , and the median and 5 per cent Trimmed mean are 3.9874 and 4.1205, respectively. Those values mentioned that the most common response for the credit risk related statements is agreed. The standard error of the mean value is 0.03386 , and the mean value is varied between the 95 per cent confidence interval of 3.9874 and 4.1205. Those values again prove that agreement is the common response for credit risk. The standard deviation of the response of the credit risk related statements is 0.65654 , and variance is 0.431 . Also, the minimum and the maximum response are respectively 1.00 and 5.00. The range of the response is 4.00, and the interquartile range is 1.00 . Which mean the response do not highly deviate from the mean value because of lower variance and interquartile range. Therefore, the responses are not highly deviated from the common response. The skewness is -0.761 , and it means the data set has left tailed distribution. The kurtosis is 1.144 , and it is a peak distribution. The left tail peak distribution means a negatively skewed distribution. Which mean the response of credit risk related statements is highly skewed to the agree side. It has presented in Figure 5.

\subsection{Regression Analysis}

Simple regression analysis is used to show the relationship where one independent variable is hypothesized to affect one dependent variable. InThisrticle tried to build the relationship Effective Risk Management has a positive relationship towards Suitability of the Microfinance Industry in Sri Lanka. In this study, the researcher obtained information from the target demographic on how they see risk management and how much support they would receive to remain in business. The research is unique in that most previous studies have obtained input from MFI firm personnel. However, this study gathered information from the end-user women microfinance consumers. A straight line is represented by a simple linear equation, which depicts the link between good risk management and the sustainability of the microfinance business.

Table 1

Simple Linear Regression Analysis

\begin{tabular}{llll}
\hline R-Square & \multicolumn{1}{c}{ Adjusted R-Square } & F-Statistic & Significance \\
\hline $\mathbf{0 . 5 1 9}$ & 0.518 & 403.826 & 0.000 \\
\hline Variable & B & t-Statistic & Significance \\
\hline Risk Management & 0.747 & 20.095 & 0.000 \\
\hline
\end{tabular}

Source: Calculated by the researcher 
According to the table above, the R-Square value is 0.519 , and the adjusted R-Square is 0.518 . Which means there is a 51.8 per cent variability of Sustainability of the microfinance industry in Sri Lanka? The model was adequate because the significance level of F-statistics (0.000) is less than the 0.05 level of significance. And also, it was presented that risk management has a significant impact on the Sustainability of the microfinance industry in Sri Lanka because the significance level of t-Statistics (0.000) is less than 0.05 level of significance. Therefore, there is a significant impact of Risk management on the Sustainability of the microfinance industry in Sri Lanka.

Research adapted simple regression analysis, which gives you an $\mathrm{R}$ squared value. This number tells you how good your model is. The values range from 0 to 1 , with 0 being a terrible model and 1 being a perfect model. As you can probably see, 0.7 is a fairly decent model, so you can be fairly confident in your weather prediction. The estimated regression equation can be formulated as a Sustainability of microfinance industry in Sri Lanka $=1.121+0.747 *$ Risk management. According to the estimated regression equation, when increasing the risk management by 1 unit sustainability of the microfinance industry in Sri Lanka will increase by 0.747 units. its means that risk management has a strong impact on the Sustainability of the microfinance industry in Sri Lanka.

The analysis from the study gives a clear indication that risk affects a major part of MFIs, and risk factors have a significant effect on drivers of Sustainability. The hypothesis also concluded that drivers of Sustainability identified have a significant effect on MFIs. Therefore, it is recommended that MFIs in any country employ a thorough risk analysis on all their business operations to address any risk-related issue pertaining to their operations. MFIs should, as a matter of agency, design a risk manual or any risk framework to manage risk and must ensure that all existing MFIs comply with the internal risk policy and report regularly. The regulator must ensure that approval of a new license should have a comprehensive risk policy or manual as a basic requirement.

\section{DISCUSSION}

It is a universally accepted fact that the concept of microfinance is an incredibly powerful one. Microfinance may have the power to reduce global poverty while providing much-needed financial services to a sector of people that are most commonly underserved by traditional financial products. However, though we talk about the importance of microfinance, a Country like Sri Lanka is experiencing a huge gap in the industry's growth potential and its Sustainability. There are so many factors that influence the industry's sustainability, such as availability of low-cost funds, outreach, Borrowers' characteristics, Business characteristics, loan characteristics, behaviours of MFIs, target clients and many more.

The study's findings reveal a significant relationship between effective risk management and the Sustainability of the microfinance industry in Sri Lanka. Hence, it is important to discuss how risk management would be used to get desired results. Due to the influx of a larger number of players to the industry and weak monitoring mechanism, the industry has encountered lots of issues and exposed highly vulnerable, which has resulted from the question of the Sustainability of the industry. Henceforth, all stakeholders in the industry, mainly MFIs and MF clients, have a great responsibility to safeguard the industry. Failing which MF industry and as well as underline principles of microfinance would not continue in the long run. In the current economic conditions, the factual problem of MFIs is a surge of loan defaults from individual borrowers instigated by deep financial vulnerability and drop-in market activities. It has aggravated due to COVID 19 situation. Now, all financial institutions and other stakeholders realize the proactive approach and maintain strong financial stability, which would certainly mitigate the probability of negative consequences. Effective risk management process is very important to MFIs to reduce negative consequences, which means attempting to control future outcomes as much as possible by acting proactively rather than reactively. Effective risk management offers the potential to reduce both the possibility of a risk occurring and its potential impact (Savalei, 2018)

The literature indicated that MFIs themselves are responsible for loan default. Mainly deals with poor management decisions, weak risk management framework, and weak strategies, unable to understand borrowers' financial requirements. But the blame should not be put solely onto MFIs. Other factors include macro-economic factors and the borrower's family and loan group's influence (Priyankara \& Sumanasiri, 2019). Although there are stages, processors and literature in risk management, the main issue is whether stakeholders are geared enough to adopt and have appetitive to follow those. With the high competition and limited market opportunities, most players try to purposely forget those good practices and finally burn their hands. As a result, they put the entire industry in jeopardy.

It is noted that risk management is a difficult and complex task to any business and financial organization, and more and more important nowadays in a world where financial systems and economic events are linked and going hand in hand. Banking regulators and Global financial institutions have stressed risk management as an essential element of long-term success. There has been a gradual discussion to identify portfolio risk and think moving incurred risk to expected risk. With the changes in market dynamics, various risk factors, instead of depending on past performances of financials, regulators are now trying to understand the importance of the futuristic view of the behaviours and more emphasis put on the organization to identify and manage future risks as the best predictor of long-term success. This is the gradual process of moving incurred credit losses (ICL) to expected credit losses (ECL). As per the Basel Committee recommendation, in order to have sound credit risk practices, all Banks should adopt proactive credit loss measurement. (BASEL Guidance on accounting for expected credit losses 2015, IFRS 9) Although BASEL has not categorized specific sectors or financial sectors, as a proactive approach, microfinance institutes (MFIs) should also explore the possibility of adopting this guideline, at least putting some foundation to those guidelines.

The main issue is that MFIs are more concerned with creating shareholder profit than with the long-term viability of their businesses and the growth of their clientele. It would be a tragedy for all stakeholders if the organization did not build a robust risk culture. The danger might occur in a variety of ways and cannot be predicted or postponed until calamity strikes. In today's 
nimble corporate environment, one never knows when it will occur. The fundamentals of risk management are establishing the context, identifying the risk, quantifying the risk, integrating the risk, prioritizing the risk, and mitigating and controlling the risk.

There are various advantages to effective risk management: It is always preferable to detect early warning signs before a pos sible problem arises: As a result, a systematic and professional process, methodology, and approach for assessing, finding early warning signs, evaluating, and measuring risk identifies would help to prevent draining organizational management time and resources. If MFIs recognize risk in advance, providing a solution and minimizing risk would be simple. If this is the case, time might be used to expand the firm and strengthen its market position.

It is clear and observed that, like other financial institutions, MFIs place the least emphasis on risk management - their primary focus is loan issuance and recovery. Identifying the right target group for the loan, evaluating NPLs, and implementing proper treasury management are all critical aspects of surviving in the MFI market. If MFIs also consider themselves to be private money lenders, the sector will be in bad condition in the long term. MFIs, like other financial institutions, should follow the same risk management methodology and structure to ensure their long-term viability in the business.

It has been noted that MSME (Micro, Small, and Medium) entrepreneurs lack financial literacy. It is a key challenge for the industry's long-term viability. Clients would seek to diversify unrelated and dangerous business endeavours while building the business, not to mention that private spending and financial discipline would steadily erode. It has been discovered that one of the primary concerns affecting the industry's sustainability is a lack of financial literacy. MFIs should focus on building financial education for customers as a business partner or partner in progress. Investing in them will undoubtedly pave the way for risk reduction in various sectors. Although we talk about transformation, instilling financial literacy is a difficult undertaking in order to shift the inherent loss system into an effective risk culture. It is a gradual process to impact financial literacy and education in the direction of assisting MFI clients. If MFIs could do so, the following might be archived in the long term.

They were exercising effort to change one's conduct, attitude, and knowledge of financial concerns. Fundamentally, a client's financial attitude reflects his or her awareness and judgements about money concerns, application, management, and usage of financial services. Opinions and judgments change over time, and thus they are key determinants of one's behaviour. Therefore, it is expected that enhancement of the financial literacy level would certainly instill financial attitudes in clients that support informed financial behaviour in the clients' businesses and households.

Develop respective clients' approaches and strategies for risk management. It is important to understand and assess the risks in their businesses and households (Home financial management income and expenditure, consumption, education health, disasters, business failure, and over-indebtedness) and take effective steps to eliminate or reduce them. They should realize the importance of management loan funds and utilize them for productive work, generating income to repay the loan. They should not use those funds for consumption without generating any return. Same time borrowers should spend wisely the excess and save for emergencies and build their assets. They should also look at other options to use a mix of financial services including insurance to protect themselves against risks.

Assets are gradually amassed. Borrowers who have good financial education will comprehend how to invest their company return, save for financial assets, namely property, jewels, equipment, animals, and savings. This selection should be based on retained earnings and cash flows. Understanding of short-, medium-, and long-term investments are required. Most clients put their working cash in long-term investments and then become stranded. All of this is due to a lack of financial expertise.

Over-indebtedness is reduced. Clients will be able to handle their loan portfolios more professionally and effectively as a consequence of financial education. It would assist them in understanding and managing their financial costs, allocating cash for income-generating activities, settling high-cost borrowings, and so on. MF consumers will progressively shift from borrowing in the informal financial sector to borrowing in the formal financial sector, but this will rely on how well MFIs understand and adapt to the needs of microfinance clients. The client would evaluate the high cost and multiple borrowings and minimize excessive gearing levels, which would undoubtedly assist them in reducing overdue and late payments.

Support in managing their finances, fulfilling bank and personal responsibilities on schedule. Furthermore, it will assist them in educating them to preserve liquid assets in case of a need to sell assets in times of adversity rather than borrowing more and more. Finally, you have a defaulter and a bankrupt. As a result, in the current environment, it is clear that risk management cannot be practised in isolation; both MFIs and Borrowers must grasp the seriousness, why risk exists, and how it should be managed. To ensure the industry's long-term viability, everyone must shoulder some of the burdens.

\section{CONCLUSION}

There has been a momentous growth in the Microfinance industry during the last two decades in Sri Lanka, particularly during the last decade. We could see the momentum would certainly grow in the next decade as well. Such growth should align with the Sustainability of the industry and not the short-term sustainability strategies and tactics of MFIs performances. The challenge for MFIs is to manage growth while ensuring adequate institutional systems to support their mission and values. Very rapid growth could dilute an MFI's mission and values and possibly increase client vulnerability. MFIs need to put clients first, especially their target clients. Ultimately, being customer-focused is one of the best risk management strategies. There was not much research carried out in Sri Lanka to ascertain actual risk management feedback from clients on how they understand, perception and expectations on MFIs from the Risk management perspective. Most of the studies have only focused on MFIs and survey samples merely from officials, not the end-user. Thus, this study has built an opportunity to carry out descriptive research to find the significance of other influential factors that impact the Sustainability of the microfinance industry in Sri Lanka. The researcher believes the hat contents and discussions in this article represent the tip of the iceberg in understanding the importance of the Microfinance industry and Risk management. Further analysis is required to help identify determinants of 
MFI behaviour and cause-and-effect relationships. Not only that going forward, we should find out how to synergize factors mainly effective risk management and women borrowers, towardsthe Sustainability of the microfinance industry in Sri Lanka.

\section{REFERENCE}

Al-Tamimi, H. A. H. (2002). Risk management practices: an empirical analysis of the UAE commercial banks. Finance India, 16(3), 1045.

Al-Tamimi, H. A. H., \& Al-Mazrooei, F. M. (2007). Banks' risk management: a comparison study of UAE national and foreign banks. The Journal of Risk Finance, 8(4), 394-409. doi:https://doi.org/10.1108/15265940710777333

Asadli, A., de Mesquita, J. B., \& Kazantseva, E. DRIVERS AND IMPACTS OF IMPACT INVESTORS IN LEAST DEVELOPED COUNTRIES (LDCs).

Bhatt, N., \& Tang, S. Y. (2001). Delivering microfinance in developing countries: Controversies and policy perspectives. Policy studies journal, 29(2), 319-333.

Cohen, J. (1988). Statistical power analysis for the behavioral sciences 2nd ed Hillsdale NJ Erlbaum.

Fernando, N. A. (2007). Managing microfinance risks: Some observations and suggestions. Asian Journal of Agriculture and Development, 4(2), 1-22. doi:10.22004/ag.econ.166009

Guardiola-Albert, C., Díez-Herrero, A., Amerigo Cuervo-Arango, M., Bodoque, J. M., García, J. A., Naranjo-Fernández, N., \& Aroca-Jiménez, E. (2020). Analysing flash flood risk perception through a geostatistical approach in the village of Navaluenga, Central Spain. Journal of Flood Risk Management, 13(1), e12590. doi: https://doi.org/10.1111/jfr3.12590

Hallunovi, A., \& Berdo, M. (2018). The relationship between risk management and profitability of commercial banks in Albania. Asian Themes in Social Sciences Research, 1(2), 44-49. doi:https://doi.org/10.33094/journal.139.2018.12.44.49

Himang, C. M., Beltran, H. U., Ocampo, L., Garcia II, J. M. S., Ancheta Jr, R. A., Himang, M. M., . . Luzano, E. J. I. (2020). Acceptability Evaluation of a Developed Thermal Infrared Device for Fire Risk Management: Using the Unified Theory of Acceptance and Use of Technology (UTAUT) Model. International Journal of Sociotechnology and Knowledge Development (IJSKD), 12(3), 1-25. doi:10.4018/IJSKD.2020070101

Ilbert, O., Arnouts, S., McCracken, H., Bolzonella, M., Bertin, E., Le Fevre, O., . . Iovino, A. (2006). Accurate photometric redshifts for the CFHT legacy survey calibrated using the VIMOS VLT deep survey. Astronomy \& Astrophysics, 457(3), 841-856. doi:https://doi.org/10.1051/0004-6361:20065138

Kalu, E. O., Shieler, B., \& Amu, C. U. (2018). Credit risk management and financial performance of microfinance institutions in Kampala, Uganda. Independent journal of management \& production, 9(1), $153-169$. doi:https://doi.org/10.14807/ijmp.v9i1.658

Kanake, J. K. (2014). The effect of credit risk management on financial sustainability of microfinance institutions in Kenya. Strathmore University,

Khakhrisal, M. (2009). MicroSave India Focus Note 21.

Krejcie, R. V., \& Morgan, D. W. (1970). Determining sample size for research activities. Educational and psychological measurement, 30(3), 607-610. doi:https://doi.org/10.1177/001316447003000308

Mbah, R. E., \& Wasum, D. F. (2019). Microfinance Survival: The Impact of Credit Management on the Sustainability of Micro Finance Institutions in Cameroon. Historical Research Letter, 50, 1-7. doi:10.7176/HRL/50-05

Meyer, L. H. (2002). Inflation targets and inflation targeting. The North American Journal of Economics and Finance, 13(2), 147-162. doi:https://doi.org/10.1016/S1062-9408(02)00074-8

Ndoka, S., \& Islami, M. (2016). The impact of credit risk management in the profitability of Albanian commercial banks during the period 2005-2015. European Journal of Sustainable Development, 5(3), 445-445. doi:https://doi.org/10.14207/ejsd.2016.v5n3p445

Oluyombo, P., \& Olabisi, J. (2008). Risk management in microfinance institutions. Journal of Applied Economics, 1(1), 104112.

Priyankara, D., \& Sumanasiri, E. (2019). Determinants of Microfinance Loan Default: An Empirical Investigation in Sri Lanka. South Asian Journal of Social Studies and Economics, 4(3), 1-13. doi:10.9734/sajsse/2019/v4i330127

Raue, P. J., Brown, E. L., Meyers, B. S., Schulberg, H. C., \& Bruce, M. L. (2006). Does every allusion to possible suicide require the same response? A structured method for assessing and managing risk. Journal of family practice, 55(7), 605-613.

Razzaq, S., Maqbool, N., \& Hameed, W. U. (2019). Factors effecting the elasticity of micro credit demand in southern Punjab, Pakistan. International Journal of Social Sciences and Economic Review, 46-53.

Rozzani, N., Mohamed, I. S., \& Yusuf, S. N. S. (2017). Risk management process: Profiling of islamic microfinance providers. Research in International Business and Finance, 41, 20-27. doi:https://doi.org/10.1016/j.ribaf.2017.04.009

Savalei, V. (2018). On the computation of the RMSEA and CFI from the mean-and-variance corrected test statistic with nonnormal data in SEM. Multivariate behavioral research, 53(3), $419-429$. doi:https://doi.org/10.1080/00273171.2018.1455142 